\title{
Stunting and Combined Overweight with Stunting among Schoolchildren in Kuwait: Trends over a 13-Year Period
}

\author{
Abdullah Al-Taiara Nawal Alqaoud ${ }^{b}$ Reem Sharaf Alddinc ${ }^{c}$ Faheema Alanezi $^{\mathrm{b}}$ \\ Monica Subhakaran ${ }^{b}$ Anne Dumadag ${ }^{a}$ Ahmed N. Albatineh ${ }^{d}$ \\ aSchool of Community and Environmental Health, College of Health Sciences, Old Dominion University, Norfolk, VA, \\ USA; ${ }^{b}$ Food and Nutrition Administration, Ministry of Health, Kuwait City, Kuwait; ${ }^{c}$ HealthCare Analytics and Delivery \\ Science Institute, Eastern Virginia Medical School, Norfolk, VA, USA; ${ }^{\mathrm{d} D e p a r t m e n t}$ of Community Medicine and \\ Behavioral Sciences, Faculty of Medicine, Kuwait University, Kuwait City, Kuwait
}

\section{Highlights of the Study}

- There is a lack of data on trends of stunting in schoolchildren in Middle Eastern settings.

- This study investigated the sex- and age-specific trends of stunting and combined overweight with stunting among schoolchildren in Kuwait.

- We found an emerging upward trend in stunting among schoolboys, which highlights the need for gender-specific interventions.

\section{Keywords}

Stunting $\cdot$ Combined overweight with stunting $\cdot$ Children . Kuwait

\begin{abstract}
Objectives: This study aimed to investigate the sex- and agespecific trends of stunting and combined overweight with stunting among schoolchildren over a 13-year period in $\mathrm{Ku}$ wait. Subjects and Methods: The Kuwait Nutrition Surveillance System objectively measured the height of 172,573 schoolchildren (5-19 years) over a 13-year period (20072019). Data on gender and date of birth were extracted from school records. Stunting was defined as height 2 standard deviations (SD) below the World Health Organization growth reference median. Logistic regression models were used to
\end{abstract}

karger@karger.com www.karger.com/mpp

Karger $\stackrel{\text { ' }}{5}$

GOPEN ACCESS
(C) 2021 The Author(s)

Published by S. Karger AG, Basel

This is an Open Access article licensed under the Creative Commons Attribution-NonCommercial-4.0 International License (CC BY-NC) (http://www.karger.com/Services/OpenAccessLicense), applicable to the online version of the article only. Usage and distribution for commercial purposes requires written permission. examine the trends of stunting over the study period while stratifying by gender. Results: In males, the prevalence of stunting increased from $2.46 \%$ in 2007 to $4.18 \%$ in 2019 (p for trend $<0.001$ ). In females, the prevalence of stunting fluctuated but remained around 3.80\% in both 2007 and 2019. The odds of stunting significantly increased in the period 2017-2019 compared to the period 2007-2010 among males, adjusted odds ratio (AOR) 1.04 (95\% confidence interval $[C l]$ : 1.14-1.76); $p=0.009$, but not females, AOR $0.89(95 \%$ Cl: $0.73-1.07) ; p=0.176$. Although not statistically significant, there was a tendency for the odds of combined overweight with stunting to increase in males, AOR $1.65(95 \% \mathrm{Cl}$ : $0.90-3.04) ; p=0.087$, but not females, AOR $1.13(95 \% \mathrm{Cl}$ : $0.88-1.45) ; p=0.248$. Conclusion: Although the prevalence of stunting and combined stunting with overweight is low, there is an emerging upward trend in schoolboys that war- 
rants further investigation and monitoring. This highlights the need for gender-specific interventions to reduce nutritional abnormalities in high-income countries in the Middle East countries like Kuwait.

(c) 2021 The Author(s)

Published by S. Karger AG, Basel

\section{Introduction}

The World Health Organization (WHO) defines stunted growth as height-for-age $>2$ standard deviations below the WHO growth reference median [1]. Stunting is a major health problem worldwide, which is associated with short-term and long-term health consequences including impaired cognitive development and increased risk of child morbidity and mortality [2-4]. In fact, heightfor-age during childhood is considered the best indicator for human capital [2]. Unlike other growth abnormalities such as childhood obesity, stunting remains invisible and understudied, particularly in schoolchildren [5].

Although the prevalence of stunting is declining worldwide, it remains a major public health problem in low- and middle-income countries [6]. Globally, 26\% of children under 5 years of age are stunted, and a significant number of schoolchildren are suffering from stunting [7]. The highest burden of stunting is seen in African and south Asian countries $[7,8]$ such as Ethiopia ( $>37 \%$ of schoolchildren) $[9,10]$, Nigeria (19.6\% of children aged 10-14 years) [11], Pakistan (24\% of children aged $4-18$ years) [12], and Malaysia (19.1\% of adolescents aged 6-19 years) [13]. In China, the prevalence of stunting among adolescents aged 6-19 years is similar to that found in high-income countries (1.2\%) [14]. There is a paucity of data on the prevalence of stunted growth among schoolchildren in Middle Eastern countries with a single study estimating that 17\% of children aged 6-11 years in Egypt had stunted growth [15].

Previous studies revealed that children with stunted growth are at a higher risk of developing obesity than their peers [16-18]. One possible explanation for this is that stunted children have reduced fat oxidation, increasing the accumulation of excess fat in the body $[19,20]$. Combined overweight and stunting has attracted global attention in recent years. A few reports have assessed its prevalence; in Ghana, $1.2 \%$ of schoolchildren are stunted and overweight [21], while in rural Mexico, the combined stunting with overweight was $10 \%$ among indigenous children and 5\% among non-indigenous children [22].

In the oil-rich countries in the Middle East such as $\mathrm{Ku}-$ wait, there is a growing consensus that the prevalence of childhood obesity has increased over the last few decades. Current estimates suggest that $>48 \%$ of school-age children are either overweight or obese [23]. However, no previous report has examined the trends of stunting or the combined overweight and stunting in the last 2 decades. For the first time, we aimed in this study to investigate the sex- and age-specific trends of stunting and combined overweight and stunting among schoolchildren over a 13-year period (2007-2019) using data from the Kuwait Nutrition Surveillance System (KNSS).

\section{Methods}

\section{Study Site and Study Participants}

Approximately 25\% of Kuwait population are under the age of 19 years, among whom school enrollment is very high for both males and females. With high oil revenues in the last few decades, there has been a significant improvement in socioeconomic status with citizens enjoy a high standard of living that includes highly subsidized foods, free education, and medical care. The government of Kuwait funds the KNSS to monitor the nutritional status of the population over time and the procedures in the KNSS have been approved by the Ethics Committee at the Ministry of Health (No. 98:262/2015). Details of KNSS have been published previously [24]. KNSS select children aged 5-19 years from public schools (primary, middle, and high schools) in all provinces of Kuwait. Public schools are sex-segregated in Kuwait, and KNSS select at least one school for males and one school for females from each primary, middle, and high schools in each province. None of the schools was selected in 2 consecutive years.

\section{Data Collection and Anthropometric Measurements}

Every year, a team of data collectors who are permanently employed by the KNSS visit the schools to take anthropometric measurements. They receive training annually and follow a standard written protocol. The height of schoolchildren was measured to the nearest $0.1 \mathrm{~cm}$ using a stadiometer with full extended knees and shoes off. Participants were asked to stand with their backs against the board with the back, scapulae, and buttocks in contact with the vertical board if possible. While the legs together, the participant's position was verified from both the front and from the left side of the body. Then, the participant's head was aligned to the Frankfort horizontal plane (the horizontal line from the ear canal to the lower border of the orbit of the eye is parallel to the floor and perpendicular to the vertical backboard). Then, the moveable headpiece of the stadiometer was brought onto the upper most (superior) point on the head with sufficient pressure on hair. Weight of the participants was measured to the nearest $0.1 \mathrm{~kg}$ using calibrated digital scales $\left(\mathrm{SECA}^{\circledR}\right)$ without heavy clothing and shoes off. Sex and date of birth of schoolchildren were extracted from the school records. No data on socioeconomic status or diet are collected by the KNSS.

\section{Statistical Methods}

Data were entered into a database at the Food and Nutrition Administration, which is part of Kuwait Ministry of Health. Data forms were visually inspected for errors and completion before 
Table 1. Distribution of the study participants by age and year of the study

\begin{tabular}{lrrrrrrrrrrrrrr}
\hline Age & Year & & & & & & & & & & & \\
& 2007 & 2008 & 2009 & 2010 & 2011 & 2012 & 2013 & 2014 & 2015 & 2016 & 2017 & 2018 & 2019 \\
\hline 5 & 1,265 & 1,598 & 1,085 & 1,137 & 1,116 & 1,241 & 952 & 686 & 1,037 & 777 & 1,030 & 657 & 902 & 13,483 \\
6 & 1,268 & 1,197 & 1,214 & 1,167 & 1,182 & 1,236 & 1,184 & 1,206 & 1,170 & 1,161 & 1,191 & 1,128 & 1,149 & 15,453 \\
7 & 1,195 & 1,191 & 1,265 & 1,222 & 1,241 & 1,194 & 1,225 & 1,219 & 1,243 & 1,159 & 1,217 & 1,148 & 1,195 & 15,714 \\
8 & 1,218 & 1,062 & 1,234 & 1,176 & 1,135 & 1,150 & 1,232 & 1,192 & 1,222 & 1,168 & 1,287 & 1,200 & 1,204 & 15,480 \\
9 & 972 & 780 & 931 & 1,096 & 1,116 & 1,181 & 1,195 & 1,172 & 1,117 & 1,180 & 1,178 & 1,203 & 1,198 & 14,319 \\
10 & 487 & 480 & 461 & 1,059 & 1,010 & 1,035 & 1,417 & 1,519 & 1,033 & 1,109 & 1,129 & 1,053 & 1,038 & 12,830 \\
11 & 476 & 397 & 454 & 813 & 892 & 870 & 2,145 & 960 & 897 & 876 & 921 & 910 & 812 & 11,423 \\
12 & 494 & 515 & 479 & 915 & 850 & 917 & 2,272 & 919 & 880 & 910 & 872 & 861 & 828 & 11,712 \\
13 & 518 & 590 & 550 & 884 & 888 & 857 & 2,267 & 911 & 888 & 882 & 906 & 869 & 795 & 11,805 \\
14 & 584 & 791 & 698 & 882 & 873 & 880 & 2,264 & 846 & 918 & 862 & 885 & 842 & 787 & 12,112 \\
15 & 767 & 831 & 803 & 853 & 861 & 826 & 2,639 & 815 & 846 & 796 & 890 & 838 & 840 & 12,605 \\
16 & 764 & 922 & 846 & 890 & 858 & 915 & 2,704 & 939 & 939 & 788 & 905 & 834 & 893 & 13,197 \\
$17-19$ & 827 & 918 & 821 & 1,178 & 987 & 789 & 2,478 & 752 & 770 & 724 & 770 & 754 & 672 & 12,440 \\
\hline Total & 10,835 & 11,272 & 10,841 & 13,272 & 13,009 & 13,091 & 23,974 & 13,136 & 12,960 & 12,392 & 13,181 & 12,297 & 12,313 & 172,573 \\
\hline
\end{tabular}

data entry by the team's supervisors. After data entry, the data were continuously checked for invalid codes or biologically implausible measurements. Data for each year were cleaned and analyzed to produce the KNSS annual reports. The exact age was calculated by subtracting the date of birth of each child from the date of measurements. Height-for-age $Z$ scores were calculated according to the WHO growth reference standards [25] using STATA function "zanthro," and then stunting was defined as height 2 standard deviations $(\mathrm{SD})$ below the WHO growth reference median. Heightfor-age $Z$ scores were flagged for 34 schoolchildren as biologically implausible (either $<-6$ or $>6$ ), which were excluded from the analysis. We plotted the prevalence (95\% confidence intervals [CIs] calculated by exact binomial distribution) of stunting over the study period while stratifying by gender. We also used binned scatter plot to present the height-for-age $Z$ scores for males and females separately.

We calculated the odds of stunting over the 13-year period while stratifying by gender and adjusting for age. We used logistic regression models in STATA 14.2 to calculate odds ratios and their $95 \%$ CIs for stunting (yes $=1$, no $=0$ ) while adjusting for age and stratifying by gender fitting the main independent variable (year of measurement 2007-2010, 2011-2013, 2014-2016, and 20172019) as an indicator variable. To account for clustering effect in this analysis, we used "svy" prefix in STATA using schools as the primary sampling units. The analysis described was then repeated with the combined overweight and stunting as the binary outcome.

\section{Results}

The analysis included 172,573 schoolchildren of which 85,749 (49.69\%) were females. The distribution of the study participants by age and year of study is shown in Table 1 . The crude prevalence of stunting in the entire study period was 3.70\% (95\% CI: 3.12-4.38\%), which was not significantly different between males and females ( $4.02 \%$ vs. $3.39 \%$, respectively, $p=0.277)$. Of the whole study group $(N=172,573)$, only $2,036(1.18 \%)$ had combined overweight (including obesity defined as BMI-forage $Z$ score $>2 \mathrm{SD}$ of the $\mathrm{WHO}$ growth reference median) with stunting in the entire period.

In males, the prevalence of stunting increased from $2.46 \%$ in 2007 to $4.18 \%$ in 2019 ( $p$ for trends in odds of stunting $<0.001)$. In females, the prevalence of stunting fluctuated but remained around $3.80 \%$ in both 2007 and 2019. With respect to the combined overweight with stunting, there was an upward trend in its prevalence among schoolboys $(0.54 \%$ in 2007 and $1.77 \%$ in 2019 ; $p$ for trends in odds of combined overweight with stunting $<0.001$ ), while in schoolgirls, this remained stable during the study period ( $p$ for trends in odds of combined overweight with stunting $=0.775$ ). The prevalence of stunting and combined overweight with stunting along with their 95\% CIs over the study period in males, females, and both sexes is depicted in Figure 1. As shown in the figure, the prevalence of stunting and the combined overweight with stunting both have increased over time in males but remained stable in females. Online suppl. Fig. S1a, b (see www.karger.com/doi/10.1159/000518533) shows the trends in stunting and combined stunting and overweight over the study period in each age-group among males and females, respectively.

Table 2 shows the link between stunting and weight status at different periods of time during the study period. 


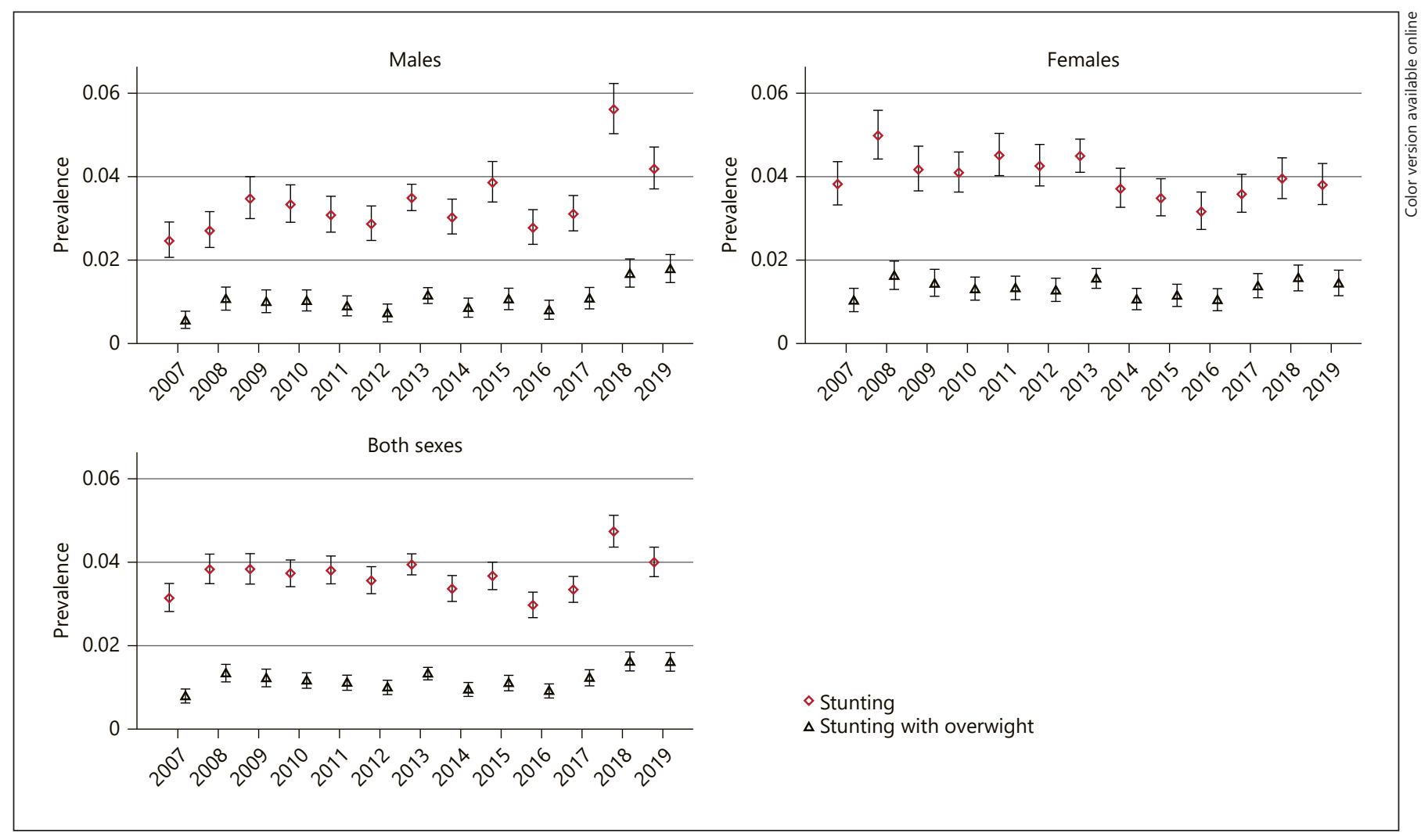

Fig. 1. Prevalence of stunting and combined stunting with overweight over the last 13 years in males, females, and both sexes.

This analysis showed that stunting was significantly higher among those with thinning than those who were overweight or obese. Although this was consistent throughout the study period, the prevalence of stunting increased among males in the period between 2016 and 2019 and became similar to that in females. Our data suggest that there is an emerging trend in stunting and combined overweight with stunting in males but not in females.

The analysis of the trends of stunting and combined stunting and overweight is presented in Table 3 . The odds of stunting significantly increased over the study period before and after adjusting for age in males but not in females. The odds of stunting in males was significantly higher in the period 2017-2019 compared to that in the period 2007-2010, adjusted odds ratio (AOR) 1.04 (95\% CI: 1.14-1.76); $p=0.009$. Similarly, the odds of combined overweight with stunting has increased in males over the study period, but this did not reach statistical significance, AOR 1.65 (95\% CI: 0.90-3.04); $p=0.087$. In females, there was no significant change in the odds of the combined overweight with stunting, AOR 1.13 (95\% CI:
$0.88-1.45) ; p=0.248$. Finally, Figure 2 illustrates the trends in height-for-age $Z$ scores over the study period, which corroborated the findings from logistic regression and showed that height-for-age $Z$ scores have declined in males but not in females. In fact, there was a tendency for the height-for-age $Z$ scores to increase in females over the study period.

\section{Discussion}

There is lack of data on the long-term trends of stunting and combined overweight with stunting in Middle Eastern settings, particularly in the oil-rich countries, where approximately $45 \%$ of schoolchildren are either overweight or obese. Regional and country-level information on trends of stunting and combined overweight with stunting are needed for planning and priority setting. In this study we examined the sex- and age-specific trends in stunting and combined stunting and overweight over the last 13 years in schoolchildren in Kuwait. We 
Table 2. Distribution of stunting by weight status in schoolchildren (5-19 years) in Kuwait between 2007 and $2019(N=172,573)$

\begin{tabular}{|c|c|c|c|c|c|c|c|}
\hline \multirow[t]{2}{*}{ Year } & \multirow[t]{2}{*}{ Weight status } & \multicolumn{2}{|l|}{ Male } & \multicolumn{2}{|c|}{ Females } & \multicolumn{2}{|l|}{ Total } \\
\hline & & $N$ & stunting, \% & $N$ & $\%$ & $N$ & stunting, \% \\
\hline \multirow[t]{4}{*}{ Overall } & Thinness & 3,029 & 8.22 & 1,894 & 6.34 & 4,923 & 7.50 \\
\hline & Normal & 43,372 & 4.11 & 45,760 & 4.79 & 89,132 & 4.46 \\
\hline & Overweight & 15,585 & 2.80 & 18,707 & 3.39 & 34,292 & 3.12 \\
\hline & Obesity & 24,838 & 1.89 & 19,388 & 2.55 & 44,226 & 2.18 \\
\hline \multirow[t]{4}{*}{ 2007-2009 } & Thinness & 711 & 6.33 & 413 & 6.30 & 1,124 & 6.32 \\
\hline & Normal & 9,116 & 3.14 & 9,483 & 4.90 & 18,599 & 4.04 \\
\hline & Overweight & 2,775 & 2.63 & 3,333 & 4.02 & 6,108 & 3.39 \\
\hline & Obesity & 3,836 & 1.77 & 3,281 & 2.71 & 7,117 & 2.21 \\
\hline \multirow[t]{4}{*}{ 2010-2012 } & Thinness & 700 & 9.71 & 396 & 8.84 & 1,096 & 9.40 \\
\hline & Normal & 9,867 & 3.67 & 10,897 & 5.18 & 20,764 & 4.46 \\
\hline & Overweight & 3,382 & 2.31 & 4,299 & 3.26 & 7,681 & 2.84 \\
\hline & Obesity & 5,374 & 1.66 & 4,457 & 2.65 & 9,831 & 2.11 \\
\hline \multirow[t]{4}{*}{ 2013-2016 } & Thinness & 754 & 10.74 & 479 & 6.05 & 1,233 & 8.92 \\
\hline & Normal & 12,519 & 4.40 & 12,341 & 5.02 & 24,860 & 4.71 \\
\hline & Overweight & 4,811 & 2.76 & 5,352 & 3.10 & 10,163 & 2.94 \\
\hline & Obesity & 8,037 & 1.72 & 5,777 & 2.49 & 13,814 & 2.04 \\
\hline \multirow[t]{4}{*}{ 2016-2019 } & Thinness & 864 & 6.37 & 606 & 4.95 & 1,470 & 5.78 \\
\hline & Normal & 11,870 & 4.93 & 13,039 & 4.18 & 24,909 & 4.54 \\
\hline & Overweight & 4,617 & 3.29 & 5,723 & 3.41 & 10,340 & 3.36 \\
\hline & Obesity & 7,591 & 2.31 & 5,873 & 2.45 & 13,464 & 2.37 \\
\hline
\end{tabular}

Stunting was defined as height-for-age $Z$ score $<-2$ SD of the WHO growth reference median. Overweight (including obesity) was defined as BMI-for-age $Z$ score $>2$ SD of the WHO growth reference median. All \% are row percentages. SD, standard deviation; WHO, World Health Organization.

Table 3. Trends of stunting and combined overweight with stunting in schoolchildren (5-19 years) in Kuwait between 2007 and 2019

\begin{tabular}{|c|c|c|c|c|}
\hline & $\begin{array}{l}\text { Stunting } \\
\text { OR }(95 \% \mathrm{CI})\end{array}$ & $p$ value & $\begin{array}{l}\text { Stunting with } \\
\text { overweight OR (95\% CI) }\end{array}$ & $p$ value \\
\hline \multicolumn{5}{|l|}{ Males } \\
\hline \multicolumn{5}{|l|}{ Year } \\
\hline 2007-2010 & 1 (reference) & & 1 (reference) & \\
\hline $2011-2013$ & $1.02(0.90-1.14)$ & 0.745 & $0.96(0.62-1.47)$ & 0.799 \\
\hline 2014-2016 & $1.06(0.87-1.29)$ & 0.479 & $0.98(0.58-1.64)$ & 0.911 \\
\hline $2017-2019$ & $1.04(1.14-1.76)$ & 0.009 & $1.65(0.90-3.04)$ & 0.087 \\
\hline \multicolumn{5}{|l|}{ Females } \\
\hline \multicolumn{5}{|l|}{ Year } \\
\hline 2007-2010 & 1 (reference) & & 1 (reference) & \\
\hline $2011-2013$ & $0.96(0.77-1.18)$ & 0.604 & $0.95(0.71-1.26)$ & 0.660 \\
\hline 2014-2016 & $0.81(0.66-0.99)$ & 0.047 & $0.84(0.54-1.30)$ & 0.345 \\
\hline 2017-2019 & $0.89(0.73-1.07)$ & 0.176 & $1.13(0.88-1.45)$ & 0.248 \\
\hline
\end{tabular}

Stunting was defined as height-for-age $Z$ score $<-2$ SD of the WHO growth reference median. Overweight (including obesity) was defined as BMI-for-age $Z$ score $>2$ SD of the WHO growth reference median. SD, standard deviation; WHO, World Health Organization; OR, odds ratio adjusted for age; CI, confidence interval. 


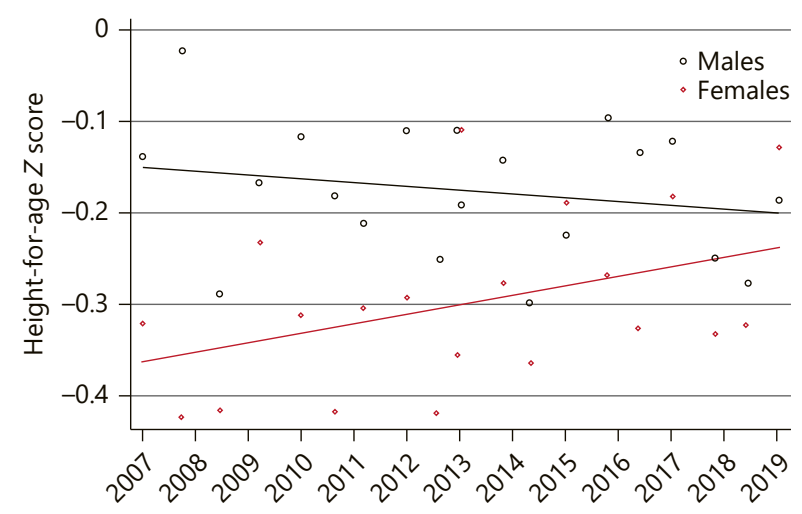

Fig. 2. Binned scatter plot for height-for-age $Z$ scores over the last 13 years for males and females.

demonstrated that the prevalence of stunting is low among schoolchildren in Kuwait, and that this has recently increased in overweight males.

The prevalence of stunting among schoolchildren in Kuwait was $3.70 \%$, which is substantially lower than the prevalence reported in low- and middle-income countries such as Egypt [15], Ethiopia [9, 10], Nigeria [26], and Mexico [27]. However, it has remained higher than that reported among schoolchildren in high-income countries like Spain [28]. At the beginning of the study period, the prevalence of stunting was slightly higher in females than in males, which is consistent with previous studies in the region [15], but in recent years, the prevalence of stunting became similar in both genders. Unlike other nutritional measures, stunting reflects long-term undernutrition in children and usually coexists with other conditions such as anemia, or recurrent or chronic infections [29]. This is not the case in Kuwait, where citizens have a high standard of living, including highly subsidized foods and free access to medical care.

Although the prevalence of stunting was low in both genders compared to several low- and middle-income countries, there is an increasing trend of stunting among males aged 5-19 years between 2007 and 2019, while the prevalence among females in the same age-group remained stable throughout the study period (Fig. 1). There is no obvious explanation for the upward trend in stunting among male schoolchildren in Kuwait, particularly with global trends for stunting declining in all age-groups $[6,8]$. However, examining the trends in stunting while stratifying by weight status showed that the prevalence of stunting has increased recently in overweight boys (Table 2). This may explain the upward trend in stunting in males, although the prevalence of combined stunting and overweight in our setting remain low overall (Fig. 1). Although low, the prevalence of combined stunting and overweight increased in boys over the study period. This emerging trend may warrant further monitoring and investigation.

A major strength of this study is the large number of participants across the age spectrum which allowed us to investigate the age-specific trends in stunting and combined overweight with stunting while stratifying by gender. We used individual data records of children based on objectively measured height instead of self-reported height by children or their parents. Previous studies have suggested that adolescents and adults overreport height [30], which may provide lower estimates of stunting. However, the study also has several limitations including the lack of data on socioeconomic status and dietary intake. Also, there were no data on chronic infections, which may coexist with stunting, but these are unlikely to be a major issue in Kuwait given free access to health-care services and public health measures in addition to arid climate. Finally, the study period covered only a 13-year period; therefore, it is possible that we reported a temporary trend and the results may change if data from a longer period of time are analyzed.

\section{Conclusion}

We observed gender differences in the trends of stunting and combined overweight with stunting in Kuwait. Although the prevalence of stunting and combined overweight with stunting is low, there is an emerging upward trend in schoolboys that warrants further investigation and monitoring. Gender-specific interventions may be required to reduce the nutritional abnormalities in highincome countries in Middle East like Kuwait.

\section{Statement of Ethics}

This study was a secondary data analysis of completely anonymous data collected by the Kuwait Nutrition Surveillance System (KNSS). All procedures of KNSS were approved by the Ethics Committee at the Ministry of Health in Kuwait (No. 98:262/2015).

\section{Conflict of Interest Statement}

There are no conflicts of interest. 


\section{Funding Sources}

There are no funding sources to declare.

\section{Author Contributions}

A.A.-T. analyzed the data and drafted the manuscript. N.A. supervised data collection, contributed to data interpretation, and revised the manuscript with significant intellectual input. R.S.A. contributed to data analysis and interpretation and revised the manuscript with significant intellectual input. F.A. supervised data collection and data entry, contributed to data management, and revised the manuscript with significant intellectual input. M.S. supervised data collection and data entry, contributed to data management, and revised the manuscript with significant intellectual input. A.D. contributed to data interpretation and revised the manuscript with significant intellectual input. A.N.A. contributed to data analysis and interpretation and revised the manuscript with significant intellectual input.

\section{Data Availability Statement}

Data belong to Kuwait Nutrition Surveillance System (KNSS), which is part of Kuwait Ministry of Health. The data can be obtained from KNSS upon reasonable request.

\section{References}

1 World Health Organization. Stunting in a nutshell. 2015. Available from: https://www. who.int/nutrition/healthygrowthproj_stunted_videos/en/ Accessed 2020 Jul.

2 Victora CG, Adair L, Fall C, Hallal PC, Martorell R, Richter L, et al. Maternal and child undernutrition: consequences for adult health and human capital. Lancet. 2008 Jan 26;371(9609):340-57.

3 Dewey KG, Begum K. Long-term consequences of stunting in early life. Matern Child Nutr. 2011 Oct;7(Suppl 3):5-18.

4 Ong KK, Hardy R, Shah I, Kuh D. Childhood stunting and mortality between 36 and 64 years: the British 1946 Birth Cohort Study. J Clin Endocrinol Metab. 2013 May;98(5):2070-7.

5 Song Y, Agardh A, Ma J, Li L, Lei Y, Stafford RS, et al. National trends in stunting, thinness and overweight among Chinese school-aged children, 1985-2014. Int J Obes. 2019 Feb;43(2):402-11.

6 de Onis M, Blössner M, Borghi E. Prevalence and trends of stunting among pre-school children, 1990-2020. Public Health Nutr. 2012 Jan; 15(1):142-8.

7 UNICEF-WHO-The World Bank. Level \& Trends in Child Malnutrition. UNICEFWHO-The World Bank Joint Child Malnutrition Estimates; 2012. p. 35.

8 Stevens GA, Finucane MM, Paciorek CJ, Flaxman SR, White RA, Donner AJ, et al. Trends in mild, moderate, and severe stunting and underweight, and progress towards MDG 1 in 141 developing countries: a systematic analysis of population representative data. Lancet. 2012 Sep 1;380(9844):824-34.

9 Bogale TY, Bala ET, Tadesse M, Asamoah BO. Prevalence and associated factors for stunting among 6-12 years old school age children from rural community of Humbo district, Southern Ethiopia. BMC Public Health. 2018 May 24;18(1):653.

10 Lisanu Mazengia A, Andargie Biks G. Predictors of stunting among school-age children in Northwestern Ethiopia. J Nutr Metab. 2018; 2018:7521751.

11 Senbanjo IO, Oshikoya KA, Odusanya OO, Njokanma OF. Prevalence of and risk factors for stunting among school children and ado- lescents in Abeokuta, southwest Nigeria. J Health Popul Nutr. 2011 Aug;29(4):364-70.

12 Ponum M, Khan S, Hasan O, Mahmood MT, Abbas A, Iftikhar M, et al. Stunting diagnostic and awareness: impact assessment study of sociodemographic factors of stunting among school-going children of Pakistan. BMC Pediatr. 2020 May 19;20(1):232.

13 Partap U, Young EH, Allotey P, Sandhu MS, Reidpath DD. Characterisation and correlates of stunting among Malaysian children and adolescents aged 6-19 years. Glob Health Epidemiol Genom. 2019;4:e2.

$14 \mathrm{Wu} \mathrm{H}$, Li H, Zong X. The prevalence of overweight, obesity and stunting in school children aged 6-19 years in Beijing, China. Ann Hum Biol. 2016 Nov;43(6):505-9.

15 El-Shafie AM, Kasemy ZA, Omar ZA, Alkalash SH, Salama AA, Mahrous KS, et al. Prevalence of short stature and malnutrition among Egyptian primary school children and their coexistence with Anemia. Ital J Pediatr. 2020 Jun 29;46(1):91.

16 Popkin BM, Richards MK, Montiero CA. Stunting is associated with overweight in children of four nations that are undergoing the nutrition transition. J Nutr. 1996 Dec;126(12): 3009-16.

17 El Taguri A, Besmar F, Abdel Monem A, Betilmal I, Ricour C, Rolland-Cachera MF. Stunting is a major risk factor for overweight: results from national surveys in 5 Arab countries. East Mediterr Health J. 2009 May-Jun; 15(3):549-62

18 Rachmi CN, Agho KE, Li M, Baur LA. Stunting coexisting with overweight in 2.0-4.9-yearold Indonesian children: prevalence, trends and associated risk factors from repeated cross-sectional surveys. Public Health Nutr. 2016 Oct;19(15):2698-707.

19 Hoffman DJ, Sawaya AL, Verreschi I, Tucker KL, Roberts SB. Why are nutritionally stunted children at increased risk of obesity? Studies of metabolic rate and fat oxidation in shantytown children from São Paulo, Brazil. Am J Clin Nutr. 2000 Sep;72(3):702-7.

20 Muhammad HFL. Obesity as the sequel of childhood stunting: ghrelin and GHSR gene polymorphism explained. Acta Med Indones. 2018 Apr;50(2):159-64.

21 Atsu BK, Guure C, Laar AK. Determinants of overweight with concurrent stunting among Ghanaian children. BMC Pediatr. 2017 Jul 27; 17(1):177.

22 Fernald LC, Neufeld LM. Overweight with concurrent stunting in very young children from rural Mexico: prevalence and associated factors. Eur J Clin Nutr. 2007 May;61(5):62332.

23 Elkum N, Al-Arouj M, Sharifi M, Shaltout A, Bennakhi A. Prevalence of childhood obesity in the state of Kuwait. Pediatr Obes. 2016 Dec; 11(6):e30-4.

24 Al-Taiar A, Alqaoud N, Hammoud MS, Alanezi F, Aldalmani N, Subhakaran M. WHO infant and young child feeding indicators in relation to anthropometric measurements. Public Health Nutr. 2020 Jul;23(10):1665-76.

25 de Onis M, Onyango AW, Borghi E, Siyam A, Nishida C, Siekmann J. Development of a WHO growth reference for school-aged children and adolescents. Bull World Health Organ. 2007 Sep;85(9):660-7.

26 Adedeji IA, Bashir MF, Shwe DD, John C. Prevalence and correlates of stunting among the school-age population in North-Central Nigeria. Pan Afr Med J. 2018;31:170.

27 Monárrez-Espino J, Martínez H, Martínez V, Greiner T. Nutritional status of indigenous children at boarding schools in northern Mexico. Eur J Clin Nutr. 2004 Mar;58(3):532-40.

28 Pérez-Ríos M, Santiago-Pérez MI, Leis R, Malvar A, Suanzes J, Hervada X. [Prevalence of malnutrition in Spanish schoolchildren]. An Pediatr. 2018 Jul;89(1):44-9.

29 Sunguya BF, Ong KI, Dhakal S, Mlunde LB, Shibanuma A, Yasuoka J, et al. Strong nutrition governance is a key to addressing nutrition transition in low and middle-income countries: review of countries' nutrition policies. Nutr J. 2014 Jun 27;13:65.

$30 \mathrm{He}$ J, Cai Z, Fan X. How accurate is the prevalence of overweight and obesity in children and adolescents derived from self-reported data? A meta-analysis. Public Health Nutr. 2018 Jul;21(10):1865-73. 